\title{
GESTIÓN DE RECURSOS NATURALES Y CONFLICTOS AMBIENTALES EN EL SEMIÁRIDO BRASILEÑO'
}

\section{MANAGEMENT OF NATURAL RESOURCES AND ENVIRONMENTAL CONFLICTS IN BRAZILIAN SEMIARID}

\author{
Roberto de Sousa Miranda ${ }^{2}$ \\ Aldo Manoel Branquinho Nunes ${ }^{3}$ \\ Laiany Tássila Ferreira ${ }^{4}$
}

\section{Resumen}

El objetivo es analizar las prácticas agropecuarias y de manejo de los recursos naturales adoptados por los agricultores familiares. Se adoptó la ecología política como referencia teórica, que parte de la idea de que la apropiación de los recursos naturales está gobernada por relaciones sociales que presionan el medio ambiente. La metodología consistió en la formulación de un perfil agrario regional y en la realización de entrevistas semiestructuradas. Los resultados demostraron que los agricultores familiares no conocen plenamente la nueva legislación ambiental y que la actuación de los organismos públicos responsables por la fiscalización ambiental es casi siempre punitiva.

Palabras clave: Agricultura Familiar, Ecología Política, Recursos Naturales, Noreste de Brasil.

\begin{abstract}
The objective is to analyse the agricultural and natural resource management practices adopted by the family agriculture. Political ecology was adopted as a theoretical reference, starts from the idea that the appropriation of natural resources is governed by social relations that put pressure on the environment. The methodological consisted in the formulation of a regional agrarian profile and in the realization of semi-structured interviews. The results showed that family agriculture is not fully aware of the new environmental legislation and that the actions of the public bodies responsible for environmental enforcement are almost always punitive.
\end{abstract}

Keywords: Family Agriculture, Political Ecology, Natural Resources, Northeast Brazil.

\footnotetext{
${ }^{1}$ Fue presentada una versión preliminar en el IX Congreso Internacional de Geografia de América Latina, en la ciudad de Toledo, España, en 2018.

${ }^{2}$ Doutor em Ciências Sociais pela Universidade Federal de Campina Grande. Professor da Universidade Federal do Agreste de Pernambuco, Garanhuns - PE, Brasil. E-mail: robertosmiranda@yahoo.com.br

${ }^{3}$ Doutor em Ciências Sociais pela Universidade Federal de Campina Grande. Professor da Faculdade Vale do Pajéu. Servidor técnico-administrativo da Universidade Estadual da Paraíba, Campina Grande - PB, Brasil. E-mail: varzeavermelha@bol.com.br

${ }^{4}$ Mestranda em Engenharia Ambiental pela Universidade Federal Rural de Pernambuco, Recife - PE, Brasil .E-mail: laianytassila@hotmail.com
} 


\section{Introducción}

Este artículo tiene como objetivo analizar las prácticas agropecuarias de los agricultores familiares de la región de Sertão Paraibano entre las décadas de 1970 y 2010, en el contexto de la crisis del algodón y del ascenso y la caída de la agricultura irrigada. La atención se dirigió a la comprensión de los conflictos ocasionados por eventuales infracciones de la legislación ambiental por parte de los agricultores familiares. El bajo volumen de agua en la Cuenca Hidrográfica Piranhas-Açu propició la suspensión, a partir del día 1 de julio de 2015, de la captación de aguas superficiales de los ríos Piancó y Piranhas-Açu, destinadas a actividades de riego y acuicultura (BRASIL, 2015).

Estas medidas fueran señaladas por muchos agricultores familiares como limitadoras e impeditivas para su subsistencia, basada en la agricultura irrigada y en la acuicultura. Este hecho, los llevaron a desarrollar estrategias productivas que contradicen dichas prohibiciones y la propia legislación ambiental, especialmente en lo que se refiere al uso de las Áreas de Preservación Permanente (APPs) y Áreas de Reserva Legal (ARL), previstas en el Código Forestal Brasileño, para el cultivo agrícola y para la ganadería.

Este cuadro contradice a una parte de los especialistas que ven a los agricultores familiares desempeñando un papel central en la seguridad alimentaria y en el desarrollo de prácticas ambientalmente "más correctas", cuando se comparan con las estrategias productivas desarrolladas por la agricultura no familiar. No es común para este campo académico hacer referencia a incumplimientos o inadecuaciones de las normas ambientales por parte de la agricultura familiar. De esta forma, los procesos productivos desarrollados por la agricultura familiar entran, muchas veces, en el centro de debates en el ámbito del desarrollo sustentable, generación de empleo y renta, producción de alimentos y desarrollo local (GUANZIROLI, 2001).

Sin embargo, existen trabajos que interpretaron las contradicciones y el uso efectivo de los recursos naturales como conflictos ambientales y demostraron que existían casos en los que algunos agricultores familiares incumplían la legislación ambiental cuando utilizaban las APPs y las ARLs para cultivos alimentarios y criar animales. No obstante, en relación a otras normas -especialmente en las que se refiere al manejo maderero de las ARLs y de la prohibición de caza, pesca y control de quemas-, algunos agricultores familiares llevaban a cabo una gestión muy eficiente (CUNHA; NUNES; MIRANDA, 2006, CUNHA; SILVA; NUNES, 2008).

La legislación ambiental es fundamental para regular y garantizar la conservación de la biodiversidad y la protección de la flora y la fauna. Mientras tanto, el proceso de elaboración del Nuevo Código Forestal Brasileño no ocurrió mediante un amplio debate entre los sectores de la sociedad que se veían afectados directamente por la legislación, especialmente los grupos sociales de baja representatividad en el Congreso Nacional, como los agricultores familiares. El resultado de este proceso fue la generación de conflictos a partir de una "concienciación ecológica" vertical, derivada de diferentes intereses (PEREIRA, 2013).

El artículo está estructurado en seis apartados. En primer lugar, presentamos el diseño metodológico de la investigación para, a continuación, debatir, en segundo lugar, sobre la ecología política y los conflictos ambientales. En el tercer exponemos los datos y la descripción de la agricultura familiar y de la nueva legislación ambiental brasileña. En el cuarto analizamos los usos de los recursos naturales por los agricultores familiares y, en el quinto, investigamos la producción agropecuaria familiar y los diferentes conflictos ambientales en Sertão Paraibano. Finalmente, concluimos con algunos postulados de la ecología política sobre la fragilidad del proceso de legitimación del discurso ambiental y sobre la exigencia que reciben los agricultores para que dejen de producir bajo el argumento de que las prácticas productivas pueden agotar los recursos naturales. Esto último oscurece el discurso velado en favor de la priorización de los intereses urbanos.

\section{Diseño metodológico}

La investigación fue realizada en las Microrregiones de Sousa y de Piancó (Figura 1), en la Cuenca Hidrográfica Piranhas-Açu, y ordenada en tres etapas: la consulta al Sistema de Recuperação Automática do Instituto Brasileiro de Geografia e Estatística (SIDRA/IBGE) para elaborar un perfil de la agricultura familiar; la definición de las comunidades ribereñas a ser estudiadas después de una consulta hecha a las oficinas regionales de la Empresa de Assistência Técnica e Extensão Rural da Paraíba (EMATER-PB) y a la base cartográfica del Instituto Brasileiro de Geografia e Estatística (IBGE) para corregir errores en la distribución geográfica (IBGE, 2006), 
ya que la EMATER-PB no disponía de información actualizada; y la evaluación del uso efectivo del suelo y de la deforestación, mediante el análisis de imágenes de satélite.

Figura 1: Localización de la Microrregión de Sousa y del Municipio de Coremas, Sertão Paraibano.

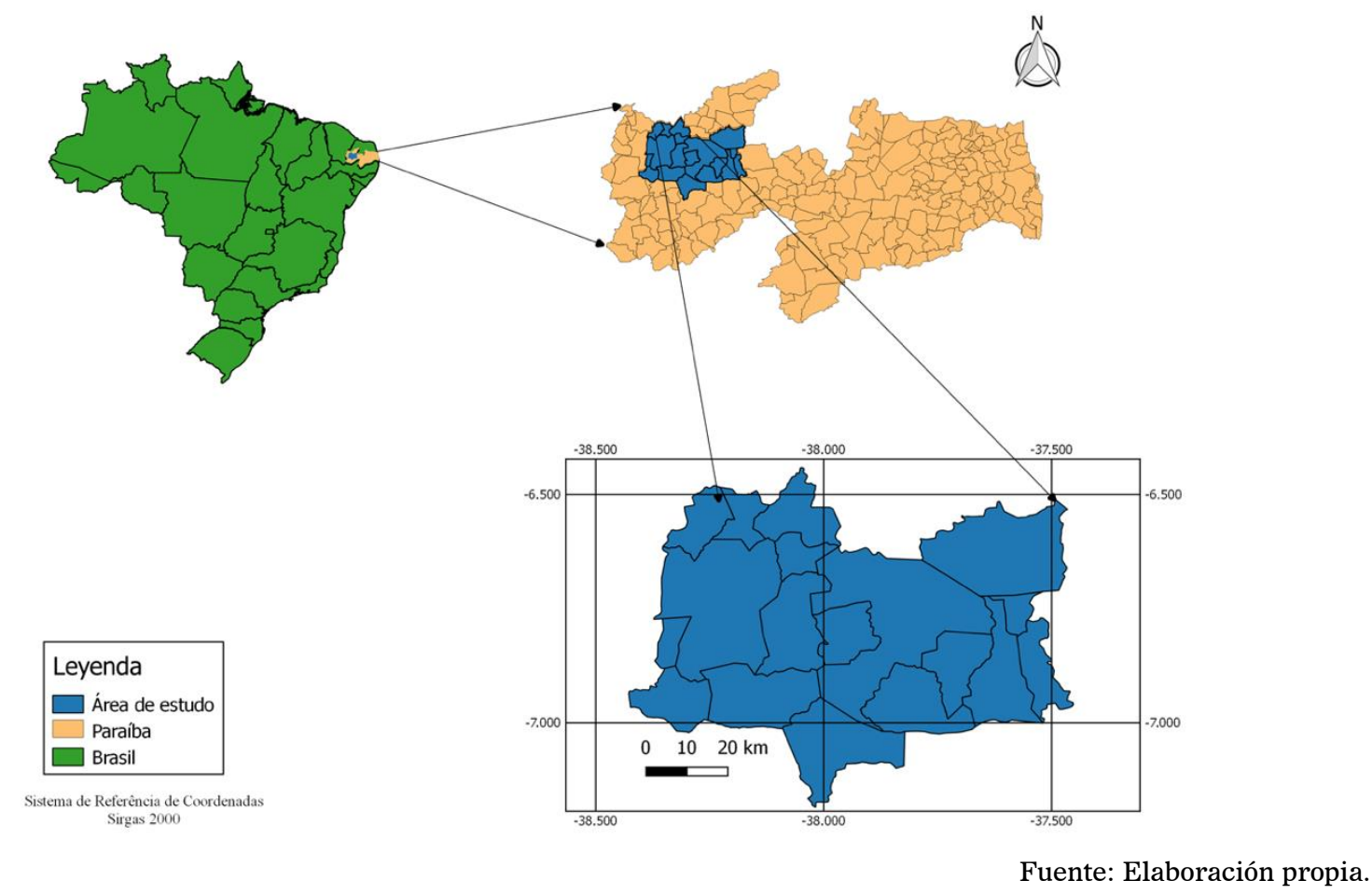

Entre 2016 y 2017 se realizaron visitas a los agricultores familiares de dichas comunidades ribereñas para realizar entrevistas, a partir de un guión semiestructurado, con el objetivo de obtener información sobre diferentes aspectos como las principales fuentes de ingresos; las prácticas productivas y de preservación ambiental; la utilización productiva de las APPs y las ARLs; el nivel de comprensión de la legislación ambiental; y la presencia y actuación de los órganos de fiscalización y gestión de los recursos naturales. Se realizaron un total de 91 entrevistas en los municipios de Aparecida, Cajazeirinhas, Nazarezinho, Paulista, Pombal y Sousa (Microrregión de Sousa) y en Coremas (Microrregión de Piancó).

A lo largo de la investigación, se intentó visitar el mayor número posible de comunidades ribereñas para poder recoger sus coordenadas geográficas por medio de la tecnología Global Position System (GPS). Esta tecnología posibilitó la elaboración de mapas y el análisis de imágenes de satélite de los años 1987, 1997, 2007 y 2016, a fin de evaluar el uso efectivo del suelo y verificar el proceso de deforestación, mantenimiento o retroceso del bosque ribereño en el curso de los ríos. Esta acción permitió examinar los impactos ambientales generados por la agricultura familiar bajo una óptica de larga duración.

Finalmente, se realizó el tratamiento de imágenes de los satélites LANDSAT 5 y LANDSAT 8, disponibles en el sitio web de United States Geological Survey (USGS), a partir del software Qgis para la elaboración de mapas temáticos utilizados en la verificación del uso y la ocupación del suelo en el área de estudio entre los años 1987 y 2016. Se tomaron en consideración no solo los municipios elegidos para las fases anteriores, sino también toda la Microrregión de Sousa y el municipio de Coremas, que alberga el embalse de Curemas/Mãe-D'água, uno de los responsables de los caudales continuos de los ríos Piancó y Piranhas-Açu.

\section{La ecología política y los conflictos ambientales}

La ecología política es un campo de investigación originado a finales de la década de 1960 y principios de la década de 1970, época en que las explicaciones para los problemas ambientales se basaban en el crecimiento poblacional, las tecnologías inadecuadas y la mala gestión de los recursos naturales; todos ellos eran argumentos claramente apolíticos. En las décadas siguientes, la ecología política reflexionó, en primer lugar, sobre la distribución desigual de los beneficios y de los costos 
asociados a los cambios sociales y ambientales, reforzando la desigualdad social y económica (BRYANT; BAILEY, 1997) y, en segundo lugar, sobre los procesos de industrialización, desindustrialización y degradación ambiental derivados de la globalización neoliberal (PEET; ROBBINS; WATTS, 2011).

No se puede negar, en consecuencia, que desde sus inicios la ecología política intentó investigar los procesos de valorización y apropiación de los recursos naturales y se constituyó en un terreno de lucha para la desnaturalización de la naturaleza. Gracias a dicha desnaturalización, la ecología política incorporó al debate las relaciones de poder como mediadoras en las relaciones entre los seres humanos y la naturaleza (LEFF, 2003). De este modo, la degradación ambiental es fruto de la interacción de diferentes actores sociales y de procesos políticos (LASCHEFSKI; COSTA, 2008) que son el resultado de las relaciones de poder (MIRANDA, 2013).

Para los ecologistas políticos las acciones de conservación de la naturaleza generan conflictos cuando: privatizan los recursos naturales (ROBBINS; LUGINBUHL, 2007); crean unidades de conservación que restringen el libre movimiento de cazadores y recolectores (COELHO; CUNHA; WANDERLEY, 2010); establecen las cadenas en la producción de alimentos, usadas por las grandes corporaciones, para explotar a los pequeños productores y a las cooperativas (EDEN, 2011). La evaluación de los proyectos de conservación es fundamental para la comprensión de las estructuras institucionales que engloban la naturaleza, la integración local y global, y los intereses de los países ricos (BUMPS; LIVERMAN, 2011).

La ecología política se desarrolló en torno a cuatro temas: la idea de que el uso de los recursos naturales se organiza a partir de las relaciones sociales que presionan la base de los mismos; el reconocimiento de la pluralidad de posiciones, intereses y racionalidades, de modo que el lucro de una persona puede representar la pobreza de otra; la idea de que hay una conexión global a través de la cual los procesos políticos y económicos estructuran los espacios locales y los influencia; y la defensa de que la degradación de la tierra es, al mismo tiempo, el resultado y la causa de la exclusión social (GEZON; PAULSON, 2004).

En Brasil, la ecología política se centró en la lucha de los movimientos sociales, rurales y locales por el acceso a la tierra (WOLFORD, 2007), en asociación con movimientos sociales latinoamericanos (MILANI, 2008); sobre los conflictos y los cambios ambientales (MIRANDA, 2013) y la gestión de los recursos hídricos (EMPINOTTI, 2011, IORIS, 2009, 2012). La mirada hacia América Latina pasa por el análisis de la introducción de cultivares transgénicos en la agricultura (WAINWRIGT; MERCER, 2011), de la incorporación de la cosmovisión indígena a la legislación (GUDYNAS, 2009), del aumento de la compra de tierras por extranjeros (COSTANTINO, 2013) y de la comodificación del agua (CAMACHO, 2012; MEEHAN, 2013).

\section{Agricultura familiar y legislación ambiental}

La inserción del agricultor familiar en el ámbito social fue un proceso largo. Sin embargo, como categoría social teóricamente referenciada es relativamente reciente ya que pasó a ser utilizada por los investigadores y representantes de los trabajadores rurales en la década de 1990 (NEVES, 2007, PICOLOTTO, 2014). Su definición no es consensual con dos visiones dominantes: una cuantitativa, que toma como base la predominancia del trabajo familiar en relación al trabajo contratado y el tamaño del establecimiento agropecuario (BUAINAIN, 2007); y una cualitativa, que analiza los aspectos familiares de este tipo de agricultura, resaltando la cultura local, la organización social y las estrategias productivas y económicas adoptadas por los agricultores (NEVES, 2007; CARNEIRO, 2008).

\section{Agricultura familiar y políticas publicas}

Hasta la década de 1990, los productores rurales, hoy reconocidos como agricultores familiares, eran definidos como pequeños productores, productores de subsistencia o como productores de bajos ingresos. Esto se modificó a partir de la lucha de movimientos sociales, para tener acceso a políticas públicas que facilitaran créditos para prácticas agrícolas y fueran capaces de promover el aumento de los precios de las producciones agrarias. Además, la reglamentación legal de la previsión social rural dio inicio al proceso de conceptualización y conocimiento de este 
sector como agricultura familiar, objetivando, por consiguiente, la elaboración de políticas públicas (CHEUNG, 2013, MATTEI, 2014).

La legitimación y reconocimiento de la agricultura familiar estuvo marcada por tres momentos principales. En primer lugar, en el ámbito de la política, la definición surge como respuestas a los movimientos sindicales, de mediados de la década de 1990, que buscaban la seguridad social y económica para los individuos que se encuadraban en esa nueva categoría. El segundo se refiere a las respuestas a los movimientos sindicales, que presionaron a los poderes públicos para elaborar e implementar, en 1996 el Programa Nacional de Fortalecimiento da Agricultura Familiar (PRONAF). El tercero, no menos importante, fue la mayor preocupación del mundo intelectual y académico brasileño, reflejada en las investigaciones enfocadas al medio rural y a la producción agrícola (SCHNEIDER, 2003).

El PRONAF representa el marco de la legitimación del término y de la categoría agricultura familiar anteriormente privada de cualquier beneficio público (MATTEI, 2014). Desde el punto de vista legal, la Ley n. ${ }^{\circ} 11.326$, de 24 de julio de 2006, establece las directrices para la formulación de la Política Nacional de la Agricultura Familiar y los Emprendimientos Familiares Rurales y define, en el artículo 3, el agricultor familiar, en los siguientes términos: es aquel que practica actividades en el medio rural, no tiene un área mayor que 4 módulos fiscales, utilice mano de obra de la propia familia en las actividades productivas, tiene renta familiar originada de actividades del propio establecimiento y dirija su establecimiento con su familia (BRASIL, 2006a).

Es importante resaltar que los agricultores familiares son reconocidos por la producción de diferentes tipos de productos, fundamentales no sólo para la alimentación de la propia familia, sino también para la población en general. Por tanto, al ofrecer estos productos al mercado se constituyen en actores importantes para la seguridad alimentaria y la preservación de la naturaleza (FINATTO; SALAMONI, 2008). Por lo demás, la agricultura familiar contribuye a la generación de empleo y puede ser considerada un factor para la reducción del éxodo rural y para la generación de ingresos en el campo (GUILHOTO et al., 2007).

La Ley $\mathrm{n}^{\circ}$ 11.346, de 15 de septiembre de 2006, que instituyó el Sistema Nacional de Segurança Alimentar e Nutricional (SISAN), destaca que la agricultura familiar es la principal proveedora de productos para asegurar una alimentación adecuada y establecer el origen y la calidad de los alimentos que se distribuirán a la población. La seguridad alimentaria y nutricional comprende:

(...) a ampliação das condições de acesso aos alimentos por meio da produção, em especial da agricultura tradicional e familiar, do processamento, da industrialização, da comercialização, incluindo-se os acordos internacionais, do abastecimento e da distribuição dos alimentos, incluindo-se a água, bem como da geração de emprego e da redistribuição da renda (BRASIL, 2006b).

De esta forma es innegable la importancia de la agricultura familiar para la seguridad alimentaria de la población brasileña, debido a la diversidad de cultivos producidos por este segmento productivo (FINATTO; SALAMONI, 2008). Además del PRONAF y del SISAN, otros programas gubernamentales buscan valorizar e incentivar la explotación sustentable de los recursos naturales por parte de las comunidades tradicionales y de los agricultores familiares: el Plano Nacional de Promoção das Cadeias de Produtos da Sociobiodiversidade, la Política Nacional de Desenvolvimento Sustentável dos Povos e Comunidades Tradicionais (PNPCT) y el Programa Federal de Manejo Florestal Comunitário e Familiar (PMCF) (PINTO, 2014).

\section{Legislación ambiental brasileña y conflictos ambientales}

El debate sobre las cuestiones ambientales que se generó en la demarcación de áreas protegidas se debe a la recurrencia del uso desordenado de los recursos naturales a lo largo del siglo $\mathrm{XX}$, así como la ocupación insustentable del medio físico por parte de la sociedad global. Las áreas legalmente protegidas se establecen para delimitar un espacio a ser conservado por medio de la reducción en el uso de los recursos naturales allí presentes, para generar beneficios ambientales y en consecuencia para mejorar la calidad ambiental (MEDEIROS, 2006).

Los intereses por las acciones conservacionistas aparecieron por primera vez en la Constitución Brasileña de 1934, ya que las cuestiones ambientales presentaban una gran importancia 
para el país en ese momento (CASTELO, 2015). El punto de partida de los legisladores respecto a la protección y preservación de los recursos ambientales se dio con la elaboración e implementación del Código de las Aguas, del Código de Minas y del Código Forestal en 1934, englobado bajo dos perspectivas: "a racionalização do uso e exploração dos recursos naturais e a definição de áreas de preservação permanente” (SALHEB et al., 2009).

El Código Forestal de 1934 contiene algunas normas ambientales "revolucionarias". A partir de este código, el uso y ocupación de las propiedades rurales quedó limitado, siendo exigida la preservación del $25 \%$ del área de las explotaciones de manera que la prioridad consistía en proteger los bosques sin afectar al mercado maderero (PRIOSTE et al., 2009). Bajo las presiones sobre la necesidad de crecimiento económico del país, en 1965 se estableció la Ley n. ${ }^{\circ} 4.771$, de 15 de septiembre, que revocó el decreto de 1934 (CASTELO, 2015) y estableció el Código Forestal Brasileño de 1965. Este último presenta como principal novedad la promoción de la relación pacífica entre el acto de preservar y realizar el manejo sustentable de los recursos naturales con las prácticas de uso y ocupación del suelo (BRANCALION; RODRIGUES, 2010).

En 2001, se promulgó la Medida Provisional n. ${ }^{\circ}$ 2.166-67, de 24 de agosto, con el propósito de modificar el Código Forestal en vigor, trayendo el concepto y obligatoriedad de APPs y de ARLs (FASIABEN, 2011). Sin embargo, se produjeron nuevas modificaciones en las prácticas de protección y preservación ambiental. El 25 de mayo de 2012 fue promulgada la Ley n. ${ }^{\circ}$ 12.651, que estableció el Nuevo Código Forestal. En el artículo 1 de dicha ley se resalta que:

(...) estabelece normas gerais sobre a proteção da vegetação, áreas de Preservação Permanente e as áreas de Reserva Legal; a exploração florestal, o suprimento de matéria-prima florestal, o controle da origem dos produtos florestais e o controle e prevenção dos incêndios florestais, e prevê instrumentos econômicos e financeiros para o alcance de seus objetivos (BRASIL, 2012).

Algunos conceptos se dilucidan en el artículo 3 de la Ley n. ${ }^{\circ} 12.651$, en el sentido de definirlos y unificar su comprensión, a efectos de interpretación de la ley. Para este trabajo, se destacan las definiciones de APP y ARL y sus respectivas funciones. APP es el área protegida, cubierta o no por vegetación nativa, con la función ambiental de preservar los recursos hídricos, el paisaje, la biodiversidad, facilitar el flujo génico de fauna y flora, proteger el suelo y asegurar el bienestar de las poblaciones humanas. ARL es el área ubicada en el interior de una propiedad o posesión rural, con la función de asegurar el uso económico de modo sustentable de los recursos naturales de la explotación rural, auxiliar la conservación y la rehabilitación de los procesos ecológicos y promover la conservación de la biodiversidad (BRASIL, 2012).

La parcela territorial que se exige que los propietarios de explotaciones destinen y preserven para la composición de la ARL, se define de acuerdo con las características del bioma y de la región en la cual que está situada la explotación. El artículo 12 del Nuevo Código Forestal Brasileño establece:

Todo imóvel rural deve manter área com cobertura de vegetação nativa [...] observados os seguintes percentuais mínimos em relação à área do imóvel [...]: I - localizado na Amazônia Legal: a) 80\% (oitenta por cento), no imóvel situado em área de florestas; b) 35\% (trinta e cinco por cento), no imóvel situado em área de cerrado; c) $20 \%$ (vinte por cento), no imóvel situado em área de campos gerais; II - localizado nas demais regiões do País: 20\% (vinte por cento). (BRASIL, 2012).

La legislación ambiental fue elaborada sin un análisis previo de sus efectos en la sociedad y sin tener en cuenta las medidas necesarias para familiarizar a la población con las nuevas reglamentaciones, resultando en conflictos sociales con agricultores familiares ubicados en áreas sujetas a la protección ambiental. La inserción de las APPs trae beneficios para el medio ambiente y aporta medios para el uso sustentable de los recursos comunes por parte de la población (AVANCI, 2009). Al establecer normativas que limitan la utilización de los recursos naturales, anhelando la protección ambiental y el bienestar de las generaciones presentes y futuras, es posible que los agricultores familiares resulten perjudicados económicamente a lo largo del proceso de adecuación de sus establecimientos rurales a las APP y ARL (NEUMANN; LOCH, 2002). 
La implementación de áreas protegidas puede ser entendida como la valorización de los recursos naturales, ejercida mediante la limitación del uso de estos y la ocupación de esas áreas para preservar la vegetación nativa de la región, las especies en peligro de extinción y otras especies del ecosistema. No obstante, la existencia de las APPs genera conflictos entre los grupos sociales y los poderes públicos, que presentan expectativas diferentes en cuanto al uso y ocupación de las áreas protegidas. Las críticas dirigidas a la exigencia de mantenimiento de áreas protegidas son fortalecidas por el argumento de que las medidas restrictivas afectan principalmente a aquellos con menor disponibilidad de tierras, es decir, a los agricultores familiares, que se ven imposibilitados de producir en toda la propiedad, reduciendo la actividad económica familiar (FASIABEN, 2011).

\section{El uso de recursos naturales y los cambios ambientales}

Para evaluar las dinámicas de cambio ambiental ocurridas a lo largo de tres décadas, especialmente, en el entorno de las comunidades rurales, ubicadas en los márgenes de los ríos Piancó y Piranhas-Açu se elaboraron un conjunto de mapas temáticos (Figura 2). Tratamos de presentar, en cada mapa (de los años 1987, 1997, 2007 y 2016) siete clases de interés útiles en la detección de cambios en el paisaje: de la vegetación, de los suelos expuestos, de la agricultura, del área urbana, del espejo de agua, de las nubes y de las sombras de nube.

Figura 2: Cambio ambiental en la Microrregión de Sousa y en el Municipio de Piancó.

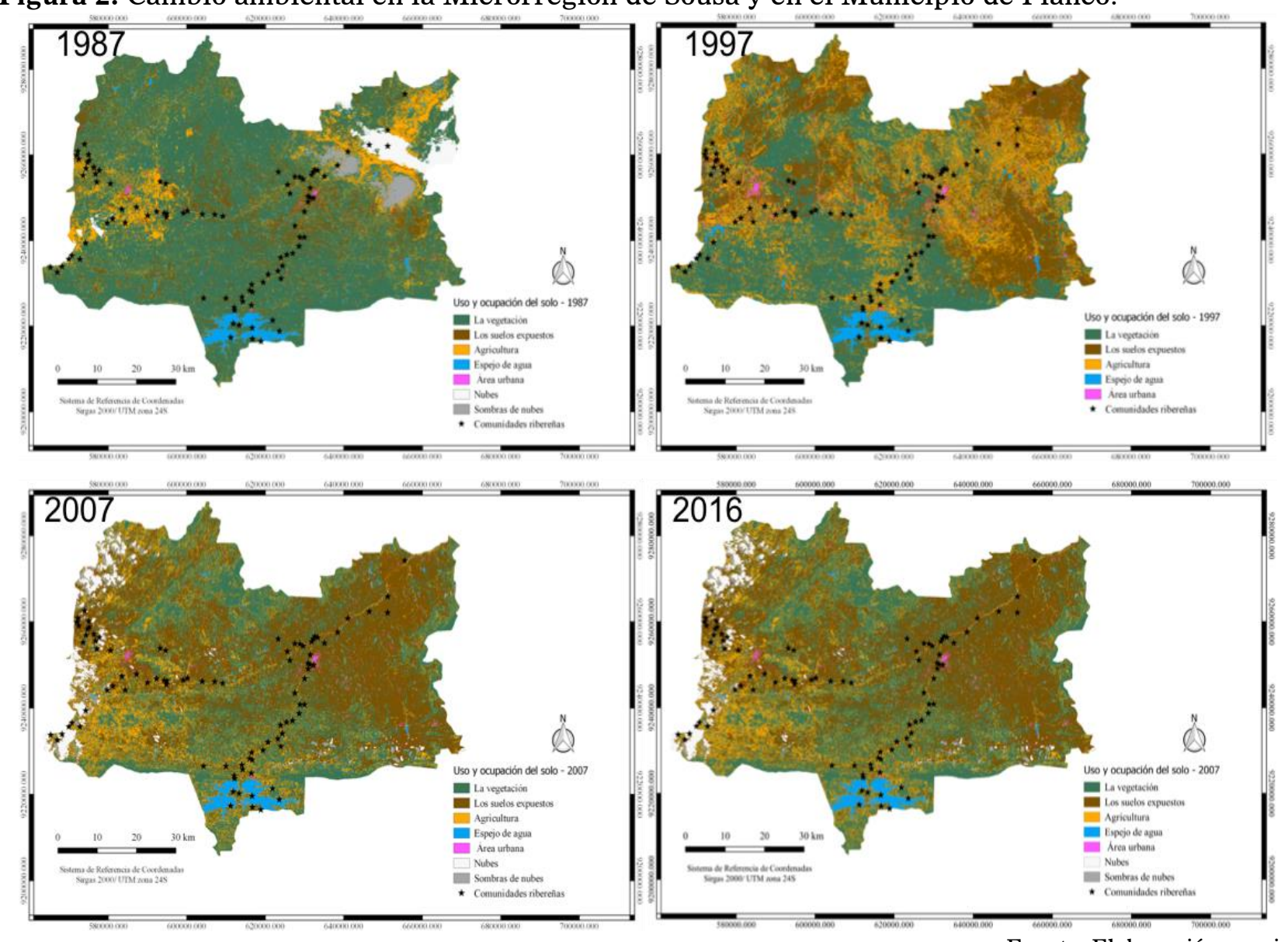

Fuente. Elaboración propia.

A partir de la clasificación de los píxeles de cada imagen, que tenían por finalidad la detección de las clases y sus respectivas representaciones en los mapas presentados arriba, fue posible cuantificar, en hectáreas, la extensión de cada una de las clases que representan el uso y la ocupación del suelo, una vez sustraídas las áreas cubiertas por las nubes. La superficie total de 518.023,3 hectáreas corresponde al área delimitada para el estudio. En el Gráfico 1, se aprecia la variación histórica de cada factor analizado (vegetación, suelo expuesto, agricultura y lámina de agua). 
Gráfico 1: Análisis comparativo bajo una óptica temporal de las áreas superficiales cubiertas por agua (a), agricultura (b), vegetación (c) y suelo expuesto (d).

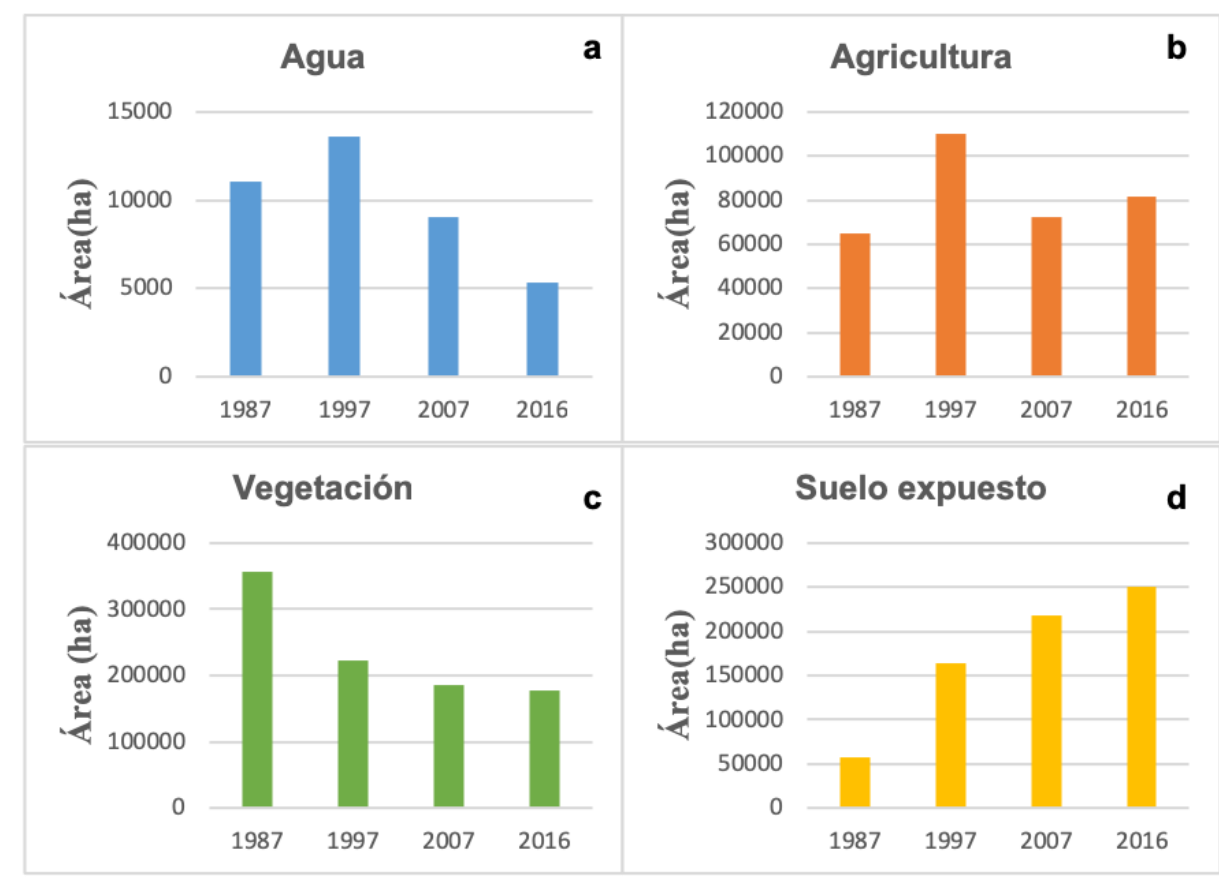

Fuente. Elaboración propia.

La producción agrícola en el área investigada muestra una aparente contradicción entre la Figura 2 y en el Gráfico 1b. De acuerdo con la Gráfica 1b, la mayor área destinada al cultivo agrícola se registró en el año 1997. Sin embargo, la Tabla 1 revela que el año 1987 observó un área dedicada al cultivo de productos agrícolas superior a los años siguientes, hecho que demuestra un proceso de reducción de las áreas destinadas a la agricultura. Esta situación es consecuencia de la clasificación de la tonalidad de los píxeles de las imágenes de satélite realizadas en el programa Qgis. Probablemente esto programa confundió píxeles de las áreas que en el año 1987 aun estaban siendo utilizadas en el cultivo del algodón, con píxeles de las áreas clasificadas como vegetación, debido a la similitud de tonalidad de estos píxeles. 
Tabla 1: Áreas destinadas al cultivo agrícola en los años 1987, 1997, 2007 y 2016 en la Microrregión de Sousa y municipio de Coremas.

\begin{tabular}{|c|c|c|c|c|c|}
\hline \multirow[t]{2}{*}{ Cultivos agrícolas } & \multicolumn{5}{|c|}{$\begin{array}{l}\text { Áreas destinadas al cultivo agrícola en cada año } \\
\text { estudiado }\end{array}$} \\
\hline & 1977 & 1987 & 1997 & 2007 & 2016 \\
\hline Algodón arbóreo & 10.2375 & 4.669 & 0 & 0 & 0 \\
\hline Algodón herbáceo & 8.998 & 1.566 & 2.902 & 1.053 & 0 \\
\hline Arroz & 4.535 & 5.834 & 1.942 & 797 & 14 \\
\hline Banana & 950 & 1.352 & 1.172 & 767 & 546 \\
\hline Papa dulce & 53 & 966 & 145 & 84 & 57 \\
\hline Caña de azúcar & 1.345 & 976 & 706 & 278 & 76 \\
\hline Coco & 158 & 220 & 836 & 1.294 & 296 \\
\hline Frijoles & 17.297 & 18.837 & 6.831 & 5.565 & 3.152 \\
\hline Guayaba & 0 & 0 & 67 & 87 & 47 \\
\hline Papaya & 0 & 0 & 9 & 0 & 0 \\
\hline Yuca & 27 & 27 & 27 & 10 & 3 \\
\hline Manga & 86 & 95 & 177 & 64 & 39 \\
\hline Sandía & 0 & 0 & 86 & 6 & 0 \\
\hline \multirow[t]{2}{*}{ Maíz } & 2.1200 & 19.446 & 9.101 & 6.420 & 3.563 \\
\hline & $\sum 157.024$ & $\Sigma 53.988$ & $\sum 24.001$ & $\sum 16.425$ & $\Sigma 7.793$ \\
\hline
\end{tabular}

Fuente: Investigaciones Agrícolas Municipales de 1977, 1987, 1997 y 2016 (IBGE, 2018).

A partir de los datos agrícolas de 1977, donde las áreas destinadas a la agricultura (especialmente de algodón, maíz y frijol) eran mayores que en todos los años siguientes, se confirma la tendencia de abandono agrícola. Se observa que el resultado de esta tendencia fue el crecimiento de las áreas de suelo expuesto, las cuales pasaron a ser utilizadas para la plantación de pastos destinados a la alimentación de ganado con el consiguiente aumento de la ganadería. Por otro parte, cabe destacar la inversión en la agricultura irrigada en las áreas próximas a los ríos, para los cultivos de mango, guayaba, plátano y coco hasta 2007 y de especies forrajeras hacia a la alimentación intensiva de bovinos, en el período de sequía prolongada (2012-2017).

Llama la atención el aumento de las áreas destinadas a la agricultura en el año 2016 en relación con el año 2007 (Gráfico 1b). Como la región enfrentó a un largo período de sequía desde el año 2012 y los embalses presentan bajos volúmenes de agua como se muestra en el Gráfico 1a, sería de esperar la disminución del área cultivada. Sin embargo, lo que se observa en los mapas es lo contrario. La actividad agrícola registra un incremento incluso con la reducción de la precipitación y de la disponibilidad de agua. Y eso ocurre justamente en los márgenes de los ríos, lo que indica un aumento de la agricultura irrigada en las APPs, o un aumento de las áreas de pastizales en las zonas que anteriormente se utilizaban para la agricultura de secano.

\section{Producción agropecuaria familiar y conflictos}

Cuando se toma como referencia el diagnóstico emprendido en el apartado anterior, a partir de la construcción de mapas y del análisis de imágenes satélite, es posible asociar un actual contexto socioeconómico y productivo a un proceso de cambios en curso desde la década de 1970. La crisis del sistema algodón-ganadería está relacionada con el direccionamiento productivo hacia la agricultura irrigada, la cual se puso en práctica con políticas destinadas al fomento de esta actividad. 
Ante ello, se hace necesario caracterizar todo este proceso de cambio. Inicialmente, se presenta el actual perfil productivo de la región, para luego analizar las estrategias productivas y el manejo de los recursos naturales por parte de los agricultores ribereños.

\section{Algodón y agricultura de regadío}

En lo que se refiere a la producción agrícola, las afirmaciones de los agricultores con relación al fin del ciclo algodonero son enfáticas y confirman los datos ya mencionados a partir de las investigaciones realizadas por el IBGE (2006). El algodón era considerado la principal fuente de ingresos para los agricultores familiares. La renta resultante de la comercialización de la pluma beneficiaba a toda la familia involucrada en la producción y como consecuencia promovía buenas condiciones de vida. Sin embargo, según los relatos de varios agricultores, con la aparición del bicudo de algodón, hubo una reducción significativa en la producción de este cultivo.

Mientras el algodón predominaba en la región, era considerado como la principal fuente de ingresos familiares. No obstante, existen referencias a un proceso de cambio en la composición de la renta familiar. Los informes hacen alusión a la sustitución de los ingresos provenientes de la agricultura por los ingresos provenientes de políticas de transferencia de renta (Bolsa Familia y Garantía Zafra) y de prestación continuada (jubilación). Cuando se le preguntó a un agricultor de 78 años sobre la principal fuente de ingresos de la familia, tomando como referencia el lapso temporal de 40 años, informó que, en el presente, era básicamente la jubilación: "Eu cheguei aqui em 1968, era bom para agricultura, mas tinha que se esforçar para ganhar o pão de cada dia, e hoje tem muita vantagem para quem é aposentado, porque não trabalha mais, e o pão de cada dia fica mais fácil”.

En consiguiente a lo largo de esas cuatro décadas, ocurrió un proceso de cambios económicos y ambientales que repercutió en la vida de los agricultores familiares. En lo que se refiere a estos cambios, se puede dibujar el siguiente cuadro causal: la crisis del algodón que ocurrió entre las décadas de 1970 y 1980 acarreó la reducción de la renta de los agricultores, los cuales buscaron alternativas para garantizar la subsistencia invirtiendo en la ganadería, la piscicultura y el riego. Sin embargo, con los años, se observa que la jubilación y las políticas asistenciales ganaron un papel en la composición de los ingresos familiares debido a la reducción de los niveles de pluviometría y, especialmente, por las limitaciones, impuestas desde los poderes públicos, al uso del agua para la piscicultura y la agricultura de regadío.

\section{Agricultura familiar y conflictos ambientales}

El contexto de cambios económicos que implicó la reducción relativa del ingreso proveniente de la agricultura, la dificultad del acceso al agua y las limitaciones de uso de los recursos naturales generó muchos conflictos entre los agricultores familiares y los órganos gestores que fiscalizan el acceso a esos recursos. Para empezar a comprender los conflictos ambientales producidos por la reglamentación del acceso y uso de recursos naturales -comprendidos como incumplimiento de las normas que exigen el mantenimiento de APPs y ARLs y de las resoluciones que prohíben la retirada de agua de ríos, azudes y canales de los perímetros irrigados para la agricultura y la acuicultura-es necesario averiguar las causas de posibles incumplimientos, especialmente si los agricultores conocen y están familiarizados con las normas de protección de la naturaleza que se les impone.

En cuanto al cumplimiento de la legislación ambiental se procuró, inicialmente, verificar el grado de conocimiento sobre un aspecto en particular: la existencia de las normas que tratan de las APP y ARL. El análisis de las entrevistas mostró que el 35\% de los agricultores conocían el tema, el $30 \%$ nunca había oído hablar de ello y el $32 \%$ habían oído hablar, pero, no sabían con exactitud de qué se trataba ni cuál era el propósito de las APP y ARL. En el marco de esta situación, registramos datos que remiten a la actuación del Instituto Brasileiro do Meio Ambiente e dos Recursos Naturais Renováveis (IBAMA) y de la EMATER-PB, en lo que se refiere a la presentación de la legislación ambiental a los agricultores. Entre los agricultores familiares entrevistados, el $71 \%$ relató que nunca habrían recibido visitas del IBAMA.

Sólo $27 \%$ de los encuestados afirmó que el IBAMA prestó servicios de fiscalización, no obstante, en gran parte de los casos, esta fiscalización estaba destinada sólo a perseguir la caza ilegal y la realización de quemas, deforestación y extracción de arena, sin embargo, nunca para transmitir información sobre la preservación y conservación de las APP y ARL. El 2\% restante se abstuvo de 
responder. Al referirse a EMATER-PB, el 49\% de los entrevistados afirman que nunca recibieron ningún tipo de asistencia técnica o servicio de extensión rural, el $45 \%$ afirmaron que recibieron asistencia técnica en algún momento y $6 \%$ no respondieron. A continuación, un agricultor expone que la acción de EMATER-PB se limita a tratar la Garantía Zafra y que nunca vio técnicos de la institución hablar de las APP y de las ARL: "a EMATER-PB só aparecia quando era para dar o Seguro Safra. E sobre a APP e ARL, só ouvi comentários, mas eles nunca apareceram aqui não, só sei que não pode desmatar perto do rio, $100 \mathrm{~m}$ e não pode 'brocar' para plantar uma roça se não vai e leva multa" (Agricultor familiar, 51 anos).

Por otra parte, del mismo grupo de personas que recibieron visitas o del IBAMA o de la EMATER-PB, sólo el 22\% afirma que recibieron informaciones sobre la preservación y conservación de las APPs y ARLs. En el siguiente extracto, un agricultor aclara la falta de asistencia de EMATERPB y confirma la participación del IBAMA en proporcionar informaciones generales sobre las leyes de protección y preservación del medio ambiente. Al mismo tiempo, el agricultor deja ver que está cumpliendo la legislación ambiental, no por reconocer la necesidad de preservar y conservar esas áreas, sino por temor a las sanciones previstas por la ley.

En este sentido y a partir del referente teórico sugerido para comprender esos procesos sociales entendidos como conflictos ambientales, el extracto anterior revela que el agricultor actúa racionalmente en conformidad con intereses colectivos no por considerar legítimamente el discurso ambientalmente transformado en ley, sino por la presencia y actuación de las instituciones que lo amenazan con la posibilidad de aplicar sanciones. Así pues, sobre algunos agricultores que experimentaron las actuaciones de los organismos fiscalizadores y de capacitación, la acción de las instituciones fue eficaz en la legitimación del proyecto territorial de preservación y conservación de la naturaleza consubstanciado en el Código Forestal.

De todo lo presentado, se extrae que el desconocimiento, por parte de los agricultores, sobre la obligatoriedad de conservación y protección de áreas de interés ambiental, en el ámbito de sus propiedades puede estar relacionado con la ausencia de los órganos de fiscalización y capacitación -en este caso, el IBAMA y la EMATER-PB- en las comunidades y la correspondiente falta de orientaciones en asociación a esos aspectos legales. La falta de orientación y de asistencia técnica son destacados por parte de los agricultores familiares entrevistados como incentivo para que las próximas generaciones no ejerzan actividades agrícolas.

\section{Conclusiones}

Este trabajo permitió analizar las estrategias productivas desarrolladas por los agricultores familiares de la Cuenca Hidrográfica Piranhas-Açu. El análisis de imágenes de satélite y la producción de mapas temáticos permitieron constatar cambios en las dinámicas de uso y ocupación del suelo y de los recursos hídricos en la Microrregión de Sousa y en el municipio de Coremas. Se pudo observar, por un lado, la reducción de las áreas ocupadas por la vegetación y la agricultura de secano y, por otro, el aumento de las áreas de suelo expuesto y de agricultura irrigada, además de la reducción de los niveles de los embalses y cursos de agua. La interpretación de esas dinámicas está de acuerdo con el perfil regional construido con los datos censales producidos por el IBGE y confirma el contexto de cambios generados por la crisis de la agricultura de secano y la ascensión y crisis de la agricultura irrigada, asociada al casi colapso de los recursos hídricos.

Los conflictos que giran en torno a las exigencias legales de mantenimiento de APP y ARL a menudo son causados por la ineficiencia de los órganos en lo que se refiere a la divulgación de la norma, así como en relación a la ausencia de fiscalizaciones que ocasionan el desconocimiento de esas exigencias legales. Es posible relacionar el incumplimiento con el desconocimiento. Sin embargo, algunos de los que conocen las normas, de forma deliberada, resuelven incumplirlas argumentando que esas áreas son consideradas como el lugar más productivo de la propiedad. Estos agricultores prefieren infringir la ley a dejar de producir en esas áreas, pues no reconocen como legítimo el discurso ambiental alrededor de los proyectos de preservación.

Las limitaciones de la retirada y el uso del agua para riego y la acuicultura generan conflictos que resultó, a menudo, en multas y en incautación de motores-bomba. Estos conflictos se agudizaron porque los órganos gestores fueron poco eficientes en la legitimación de los discursos en torno a las limitaciones. Además, estos últimos se agravaron con las incertidumbres creadas por los cambios constantes en el contenido de las resoluciones. Para algunos agricultores que, incluso conociendo las restricciones, continúan utilizando el agua para riego y acuicultura, las restricciones no tienen 
sentido porque tienen la percepción de que este recurso está siendo desperdiciado, ya que ven la agua "pasar" sin poderla utilizar. Para ellos tampoco tiene sentido detener sus actividades económicas para garantizar el abastecimiento de las ciudades. También tienen la percepción que son los únicos que asumen los costos de la dificultad del acceso al agua.

Cuando esos conflictos son analizados con los postulados de la ecología política se constata que de hecho existe una fragilidad en el proceso de legitimación del discurso ambiental. Al exigir a los agricultores que paren de producir bajo un argumento débil de que si ellos continúan con las prácticas productivas el recurso se agota, oscurece el discurso oculto en favor de la priorización de actividades económicas e intereses urbanos. Si los órganos cumplen sus funciones de formación, capacitación y fiscalización, además de exponer con claridad el porqué de la existencia de las normas; si fueran eficientes en la legitimación del discurso ambiental exponiendo con claridad los intereses políticos y económicos; si los costes de las restricciones se dividieran entre todos los que hacen uso de los recursos naturales y si hubiera incentivos para el cumplimiento de las normas, tal vez los agricultores familiares gestionarían de manera más eficiente los recursos naturales en conexión con los principios que rigen las políticas ambientales.

\section{Bibliografía}

AVANCI, T. F. S. A reserva legal como instrumento de efetividade da proteção da biodiversidade. Revista USCS de Direito, Caxias do Sul, n. 5, p. 187-209, jan./jun. 2009. Disponível em: < http://ojs.fsg.br/index.php/direito/article/view/243 >. Acesso em: 13 ago. 2018.

BRANCALION, P. H. S.; RODRIGUES, R. R. Implicações do cumprimento do Código Florestal vigente na redução de áreas agrícolas: um estudo de caso da produção canavieira no Estado de São Paulo. Biota Neotropica, Campinas, v. 10, n. 4, p. 63-66, out./dez. 2010. Disponível em: $<$ https://doi.org/10.1590/S1676-06032010000400009 >. Acesso em: 13 ago. 2018.

BRASIL. Lei $\mathbf{n}^{\mathbf{0}}$. 11.326, de 24 de julho de 2006a. Estabelece as diretrizes para a formulação da Política Nacional da Agricultura Familiar e Empreendimentos Familiares Rurais. Disponível em: <http://www.planalto.gov.br/ccivil_03/_ato2004-2006/2006/lei/111326.htm>. Acesso em: 13 ago. 2016.

BRASIL. Lei no 11.346, de 15 de setembro de 2006b. Cria o Sistema Nacional de Segurança Alimentar e Nutricional - SISAN com vistas em assegurar o direito humano à alimentação adequada e dá outras providências. Disponível em: <http://www.planalto.gov.br/ccivil_03/_ato20042006/2006/lei/111346.htm >. Acesso em: 13 ago. 2016.

BRASIL. Lei n. 12.651, de 25 de maio de 2012. Dispõe sobre a proteção da vegetação nativa; altera as Leis $\mathrm{n}^{\mathrm{os}} 6.938$, de 31 de agosto de 1981, 9.393, de 19 de dezembro de 1996, e 11.428, de 22 de dezembro de 2006; revoga as Leis $\mathrm{n}^{\mathrm{os}} 4.771$, de 15 de setembro de 1965, e 7.754, de 14 de abril de 1989, e a Medida Provisória no 2.166-67, de 24 de agosto de 2001; e dá outras providências. Disponível em: < http://www.planalto.gov.br/ccivil_03/_ato2011-2014/2012/lei/112651.htm>. Acesso em: 13 ago. 2016.

BRASIL. Resolução conjunta ANA-IGARN-AESA no 640, de 18 de junho de 2015. Disponível em: <http://arquivos.ana.gov.br/resolucoes/2015/640-2015.pdf>. Acesso em: 13 ago. 2016.

BRYANT, R. L.; BAILEY, S. Third world political ecology. New York: Routledge, 1997

BUAINAIN, A. M. Agricultura familiar e inovação tecnológica no Brasil: características, desafios e obstáculos. Campinas: EDUNICAMP, 2007.

BUMPS, A. G.; LIVERMAN, D. M. Carbon colonialism? Offsets, greenhouse gas reductions, and sustainable development. In: PEET, R., ROBBINS, P. y WATTS, M. J. (Eds.). Global political ecology. London: Routledge, 2011, p. 203-224.

CAMACHO, F. M. Competing rationalities in water conflict: mining and the indigenous community in Chiu Chiu, el Loa Province, northern Chile. Singapore Journal of Tropical Geography, Singapura, 
v. 33, n. 1, p. 93-107, Mar. 2012. Disponível em: < https://doi.org/10.1111/j.1467-9493.2012.00451.x >. Acesso em: 13 jul. 2017.

CARNEIRO, M. J. Em que consiste o familiar da agricultura familiar? In: COSTA, L. F. C., FLEXOR, G.; SANTOS, R. Mundo rural brasileiro: ensaios interdisciplinares. Rio de Janeiro: Mauad, 2008, p. 255-269.

CASTELO, T. B. Legislação Florestal brasileira e políticas do governo de combate ao desmatamento na Amazônia Legal. Ambiente \& Sociedade, Campinas, v. 18, n. 4, p. 221-242, out./dez. 2015. Disponível em: <https://doi.org/10.1590/1809-4422ASOC1216V1842015>. Acesso em: 13 ago. 2018.

CHEUNG, T. L. Desenvolvimento da Agricultura Familiar: investigação sobre o espaço rural e o território como referência para estudar o caso do município de Terenos, MS. Interações, Campo Grande, v. 14, n. 2, 189-195, jul./dez. 2013. Disponível em: <https://doi.org/10.1590/S151870122013000200005 >. Acesso em: 13 ago. 2018.

COELHO, M. C. N.; CUNHA, L. H.; WANDERLEY, L. J. M. Conflitos em áreas de mineração na Amazônia: os casos dos quilombolas e dos moradores de beiras de lagos, dos canais fluviais e de estradas em Oriximiná. In: ZHOURI, A.; LASCHEFSKI, K. (Ed.). Desenvolvimento e conflitos ambientais. Belo Horizonte: EDUFMG, 2010, p. 276-300.

COSTANTINO, A. Apuntes para una ecología política de la dependencia. El caso del acaparamiento de tierras. Revista Sociedad y Economía, Cali, n. 25, p. 39-54, jul./dic. 2013. Disponível em: $<$ http://www.scielo.org.co/scielo.php?pid=S1657-

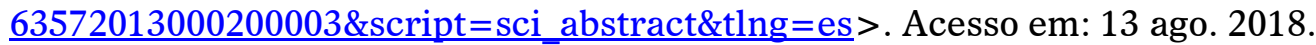

CUNHA, L. H.; NUNES, A. M. B.; MIRANDA, R. S. Colapso e reconstrução dos regimes de propriedade e o manejo dos recursos naturais em áreas de assentamento. In: ENCONTRO DA REDE RURAL, 1., 2006, Niterói. Anais..., 2006.

CUNHA, L. H.; SILVA, J. I. A. O.; NUNES, A. M. B. A proteção da Natureza em assentamentos rurais e nas RPPN's: conflitos ambientais e processos de territorialização. Revista Raízes, Campina Grande, v. 27, n. 1, p. 80-96, jan./jun. 2008. Disponível em: <https://doi.org/10.37370/raizes.2008.v27.289>. Acesso em: 13 ago. 2018.

EDEN, S. The politics of certification: consumer knowledge, power, and global governance in ecolabeling. In: PEET, R.; ROBBINS, P.; WATTS, M. J. (Eds.). Global political ecology. London: Routledge, 2011, p. 169-184.

EMPINOTTI, V. L. E se eu não quiser participar? O caso da não participação nas eleições do comitê de bacia do rio São Francisco. Ambiente \& Sociedade, Campinas, v. 14, n. 1, p. 195-211, jan./jun. 2011. Disponível em: <http://dx.doi.org/10.1590/S1414-753X2011000100011>. Acesso em: 13 ago. 2018.

FASIABEN, M. C. R. Impacto Econômico da Reserva Legal Florestal Sobre Diferentes Tipos de Unidades de Produção Agropecuária. Revista de Economia e Sociologia Rural, Brasília, v. 49, n. 4, p. 1051-1096, out/dez. 2011. Disponível em: <http://dx.doi.org/10.1590/S0103-20032011000400010>. Acesso em: 13 ago. 2018.

FINATTO, R. A.; SALAMONI, G. Agricultura familiar e agroecologia: perfil da produção de base agroecológica do município de Pelotas/RS. Sociedade \& Natureza, Uberlândia, v. 20, n. 2, p. 199-217, dez. 2008. Disponível em: <https://www.scielo.br/scielo.php?pid=S1982-

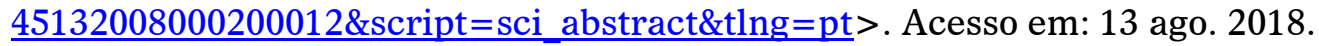

GEZON, L. L.; PAULSON, S. Place, power, difference: multiscale research at the dawn of the twentyfirst century. In: PAULSON, S.; GEZON, L. L. (Eds.). Political ecology across spaces, scales, and social groups. New Brunswick: Rutgers University Press, 2004, p. 1-16. 
GUANZIROLI, C. E. Agricultura Familiar e reforma agrária no século XXI. Editora Garamond, 2001.

GUDYNAS, E. La ecología política del giro biocéntrico en la nueva constitución de Ecuador. Revista de Estudios Sociales, Bogotá, n. 32, p. 34-46, abr. 2009. Disponível em: <http://www.scielo.org.co/pdf/res/n32/n32a03.pdf >. Acesso em: 13 ago. 2018.

GUILHOTO, J. J. M.; ICHIHARA, S. M.; SILVEIRA, F. G.; DINIZ, B. P. C.; AZZONI, C. R.; MOREIRA, G. R. A importância da agricultura familiar no Brasil e em seus estados. Brasília: NEAD, 2007.

IBGE. Censo Agropecuário 2006. Disponível em: < https://sidra.ibge.gov.br/home/pms/brasil> Acesso em: 13 ago. 2017.

IBGE. Pesquisa Agrícola Municipal. Disponível em: <https://sidra.ibge.gov.br/pesquisa/pam/tabelas >. Acesso em: 13 ago. 2018.

IORIS, A. A. R. Desenvolvimento nacional e gestão de recursos hídricos no Brasil. Revista Crítica de Ciências Sociais, n. 85, p. 23-41, jun. 2009. Disponível em: <https://doi.org/10.4000/rccs.329>. Acesso em: 13 ago. 2018.

IORIS, A. A. R. Applying the Strategic-Relational Approach to Urban Political Ecology: The Water Management Problems of the Baixada Fluminense, Rio de Janeiro, Brazil. Antipode, v. 44, n. 1, p. 122-150, Apr. 2012. Disponível em: <https://doi.org/10.1111/j.1467-8330.2011.00848.x >. Acesso em: 13 ago. 2018.

LASCHEFSKI, K.; COSTA, H. S. M. Segregação social como externalização de conflitos ambientais: a elitização do meio ambiente na APA-SUL, região metropolitana de Belo Horizonte. Ambiente \& Sociedade, Campinas, v. 11, n. 2, p. 307-322, jul./dez. 2008. Disponível em: $<$ https://doi.org/10.1590/S1414-753X2008000200007>. Acesso em: 13 ago. 2018.

LEFF, E. La ecología política en América Latina: un campo en construcción. Sociedade e Estado, Brasília, v. 18, n. 1/2, p. 17-40, jan./dez. 2003. Disponível em: < https://www.scielo.br/pdf/se/v18n12/v18n1a02.pdf >. Acesso em: 13 ago. 2018.

MATTEI, L. O papel e a importância da agricultura familiar no desenvolvimento rural brasileiro contemporâneo. Revista Econômica do Nordeste, Fortaleza, v. 45, p. 71-79, out./dez. 2014. Disponível em: <https://ren.emnuvens.com.br/ren/article/view/500 >. Acesso em: 13 ago. 2018.

MEDEIROS, R. Evolução das tipologias e categorias de áreas protegidas no Brasil. Ambiente \& Sociedade, Campinas, v. 9, n. 1, jan./jun. 2006. Disponível em: <https://www.scielo.br/pdf/asoc/v9n1/a03v9n1.pdf >. Acesso em: 13 ago. 2018.

MEEHAN, K. M. Tool-power: water infrastructure as wellsprings of state power. Geoforum, v. 57, p. 215-224, Nov. 2013. Disponível em: <https://doi.org/10.1080/2325548X.2016.1191302>. Acesso em: 13 ago. 2018.

MILANI, C. R. S. Ecologia política, movimentos ambientalistas e contestação transnacional na América Latina. Cadernos CRH, Salvador, v. 21, n 53, p. 289-303, maio/ago. 2008. Disponível em: < http://dx.doi.org/10.1590/S0103-49792008000200007>. Acesso em: 10 ago. 2017.

MIRANDA, R. S. Ecologia política e processos de territorialização. Sociedade e Estado, Brasília, v. 28, n. 1, p. 142-161, jan./abril 2013. Disponível em: <http://dx.doi.org/10.1590/S010269922013000100008>. Acesso em: 13 ago. 2018.

NEUMANN, P. S.; LOCH, C. Legislação Ambiental, Desenvolvimento Rural e Práticas Agrícolas. Ciência Rural, Santa Maria, v. 33, n. 3, p. 398-406, jun. 2009. Disponível em: < https://doi.org/10.1590/S0103-84782002000200010 >. Acesso em: 10 ago. 2018. 
NEVES, D. P. Agricultura familiar: quantos ancoradouros! In: FERNANDES, B. M., MARQUES, M. I. M., SUZUKI, J. C. Geografia agrária: teoria e poder. São Paulo: Expressão popular, 2007, p. 211270.

PEET, R.; ROBBINS, P.; WATTS, M. Global nature. In: PEET, R.; ROBBINS, P.; WATTS, M. J. (Eds.). Global political ecology. London: Routledge, 2011, p. 1-47.

PEREIRA, V. C. O novo código florestal brasileiro: dilemas da consciência ecológica em torno da proteção ambiental. Ambiente \& Educação, Campinas, v. 18, n. 1, p. 211-228, jan./jun. 2013. Disponível em: <https://periodicos.furg.br/ambeduc/article/view/3014 > . Acesso em: 13 ago. 2018.

PICOLOTTO, E. L. Os atores da construção da categoria agricultura familiar no Brasil. Revista de Economia e Sociologia Rural, Brasília, v. 52, n. 1, p. 63-84, fev. 2014. Disponível em: <http://dx.doi.org/10.1590/S0103-20032014000600004 >. Acesso em: 10 ago. 2018.

PINTO, D. M. O uso de recursos de propriedade comum em áreas de propriedade estatal por populações tradicionais e assentados da reforma agrária. 2014. Tese (Doutorado em Administração) - Universidade de Brasília, Brasília, 2014.

PRIOSTE, F. G. V.; AVANCI, J; PACHER, L.; VIEIRA, J. Mudanças na legislação ambiental e os reflexos na Agricultura Familiar camponesa e povos e comunidades tradicionais: subsídios técnicos e políticos para o debate. Curitiba: Terra de direitos, 2009. Disponível em: $<$ https://br.boell.org/sites/default/files/downloads/Estudo_sobre_Codigo_Florestall.pdf $>$. Acesso em: 13 ago. 2018.

ROBBINS, P.; LUGINBUHL, A. The last enclosure: resisting privatization of wildlife in the western united states. In: HEYNEN, N.; ROBBINS, P.; PRUDHAM, S.; McCARTHY, J. (Eds.). Neoliberal environments: false promises and unnatural consequences. London: Routledge, 2007, p. 25-37.

SALHEB, G. J. M.; PERES NETO, H. A. P.; OLIVEIRA, I. M.; AMARAL JÚNIOR, M. F.; BOETTGER, R. J. C. S.; MONTEIRO, V. C. S.; SUPERTI, E. Políticas públicas e meio ambiente: reflexões preliminares. Planeta Amazônia: Revista Internacional de Direito Ambiental e Políticas Públicas, n. 1, p. 5-27, 2009. Disponível em: < https://periodicos.unifap.br/index.php/planeta/article/view/57>. Acesso em: 13 jul. 2018.

SCHNEIDER, S. Teoria social, agricultura familiar e pluriatividade. Revista Brasileira de Ciências Sociais, São Paulo, v. 18, n. 51, p. 99-121, fev. 2003. Disponível em: < https://www.scielo.br/pdf/rbcsoc/v18n51/15988 >. Acesso em: 13 jul. 2018.

WAINWRIGT, J.; MERCER, K. L. Transnational transgenes: the political ecology of maize in Mexico. In: PEET, R.; ROBBINS, P.; WATTS, M. J. (Eds.). Global political ecology. London: Routledge, 2011. p. 412-430.

WOLFORD, W. Neoliberalism and the struggle for land in Brazil. In: HEYNEN, N.; MACCARTHY, J.; PRUDHAM, S.; ROBBINNS, P. (Eds.). Neoliberal environments: false promises and unnatural consequences. London: Routledge, 2007. p. 243-254. 